\title{
ANÁLISE DE MARCAS DE DEFORMAÇÃO EM BOBINAS DE AÇO COM GAVALIZAÇÃO BRILHANTE*
}

Claudio Pereira Diogo ${ }^{1}$ Willy Ank de Mortais²

\section{Resumo}

Bobinas de aço laminadas a frio galvanizadas com recobrimento do cromo foram empregadas para a produção de telhas e calhas d'água. Entretanto, o fabricante destes produtos teve problemas com as superfícies obtidas, que mostraram sinais de marcas de deformação/estiramento. O problema é que, na aplicação desejada, uma aparência superficial que não seja brilhante e lisa é muito indesejável. Este trabalho foi feito a fim de descrever as condições que levaram o material para se comportar como visto pelo usuário (fabricante de telhados e calhas de chuva) com base em sua aparência e comportamento mecânico. Foram empregadas observações em microscópio estéreo e curvas tensão-deformação, obtidas a partir de ensaios de tração. Com base nos resultados, são apresentadas algumas opções para minimizar a ocorrência de marcas citadas durante a utilização do que as bobinas.

Palavras-chave: Bobinas de aço; Aço laminado a frio; Galvanização; Cromação; Marcas de deformação.

\section{ANALYSIS OF DEFORMATION MARKS OCCURENCE ON STEEL COILS WITH BRIGHT GALVANIZING}

\section{Abstract}

Thin cold rolled galvanized steel coils with chromated surface were intended to manufacture steel roofs and rain gutters. However, the manufacturer of these products had problems with the surfaces obtained, which showed stretcher strain/stretch marks. The problem is that in the desired application, surface appearance whose differ from bright and smooth is highly undesirable. This work was done in order to describe the conditions that led the material to behave as seen by the user (roofs and rain gutters manufacturer) based on its appearance and mechanical behavior. Was employed stereo microscope observations and stress-strain curves, obtained from tensile tests. Based on the results, some options are presented to minimize the occurrence of the cited marks during the use of that coils.

Keywords: Steel coils; Cold mill steel; Galvanization; Chroming; Strain marks.

1 Mestre em Engenharia Metalúrgica e de Materiais pela PUC-Rio, graduação em Engenharia Metalúrgica pela EM-UFOP, técnico em Metalurgia pela ETFOP; Professor Adjunto, Faculdade de Engenharia, UNISANTA, Santos, SP, Brasil; willyank@unisanta.br.

2 Bacharelando em Engenharia de Produção, UNIMONTE, Santos, SP, Brasil; claudiopdiogo@ig.com.br. 


\section{INTRODUÇÃO}

A produção de artefatos de aço de aplicação não estrutural é tipicamente feita com o emprego de aços não ligados de baixo carbono $(\% \mathrm{C}<0,15)$. Produtos que exigem um certo grau de conformabilidade, como é o caso de telhas e calhas, normalmente podem ser obtidos com o uso de aços comerciais com teores de carbono reduzidos $(\% \mathrm{C}<0,10)$ ou com aços de baixa a média estampabilidade/conformabilidade.

Em termos de laminados a frio, algumas normas de qualidade de aços para estas aplicações, que poderiam ser selecionadas para a produção de telhas e calhas, estão descritas abaixo:

- SAE J403 $1006 ; 1008 ; 1010$ / SAE J1392 040 XLK

- ASTM A1008 CS-A ; CS-B ; CS-C / ASTM A1008DS-A ; DS-B

- $\quad$ BD 1449 S1.4 CR 4 / BS 1449 S1.4 HR4 ; HR14; HR15

- DIN 1614 P2 STW22 / DIN 1623 P1 St 12

- EN 10130 DC01; DC03 / EN 10268 H240 LA

- JIS G3141 SPCC

- NBR 5915 EM ; EP / NBR 6649 CF-21 ; CF-24 / NBR 6658

- SEW 094 ZStE 220P ; 260P

A maioria destas normas requisitam um mínimo de alongamento e descrevem os valores de limite de escoamento e resistência, conforme descrito na Tabela 1, obtida da norma ABNT NBR 5915:2008 - Bobinas e chapas finas a frio de aço-carbono para estampagem - Especificação. Porém estas normas também descrevem um prazo de validade para as propriedades mecânicas do aço. A norma NBR 5915, por exemplo, indica o prazo reproduzido na Figura 1, após o qual o aço pode apresentar envelhecimento, fenômeno descrito na norma conforme mostrado na Figura 2.

Tabela 1. Valores de propriedades mecânicas de um aço para estampagem (baixa, média e alta estampabilidade) com baixo carbono conforme a norma ABNT NBR 5915:2008.

\begin{tabular}{|c|c|c|c|c|c|c|c|}
\hline \multirow{2}{*}{ Grau } & \multirow{2}{*}{$\begin{array}{c}\text { Limite de } \\
\text { escoamento } \\
\mathrm{MPa}\end{array}$} & \multirow[t]{2}{*}{$\begin{array}{l}\text { Limite de } \\
\text { resistência } \\
\text { à tração } \\
\mathrm{MPa}\end{array}$} & \multicolumn{2}{|c|}{$\begin{array}{l}\text { Alongamento total } \\
\text { Min. } \\
\text { \% }\end{array}$} & \multirow[t]{2}{*}{$\begin{array}{l}\text { Dureza } \\
\text { Rockwell } \\
\text { HRB } \\
\text { máx. }\end{array}$} & \multirow[t]{2}{*}{$\begin{array}{l}\text { Anisotropia } \\
r_{x}^{c), d)} \\
\text { min. }\end{array}$} & \multirow{2}{*}{$\begin{array}{l}\text { Expoente de } \\
\text { encruamento } \\
\qquad n_{90}^{c)} \\
\text { min. }\end{array}$} \\
\hline & & & $\begin{array}{c}\mathrm{Lo}=50 \\
\mathrm{~mm}\end{array}$ & $\begin{array}{c}\text { Lo }=80 \\
\mathrm{~mm}\end{array}$ & & & \\
\hline EM & 280 máx. & $270-390$ & 30 & 28 & 65 & - & - \\
\hline EP & 260 máx. & $270-370$ & 35 & 33 & 57 & 1,3 & - \\
\hline EEP Grau 1 & $140-230$ & $270-350$ & 38 & 36 & 50 & 1,7 & 0,19 \\
\hline EEP Grau 2 & $140-210$ & $270-350$ & 39 & 37 & 50 & 1,9 & 0,20 \\
\hline EEP Grau 3 & $140-180$ & $270-330$ & 40 & 38 & 48 & 2,1 & 0,22 \\
\hline EEP Grau 4 & $120-160$ & $250-330$ & 42 & 40 & 48 & 2,3 & 0,23 \\
\hline \multicolumn{8}{|c|}{$\begin{array}{l}\text { a) Para bobinas e chapas de espessuras menores ou iguais a } 0,5 \mathrm{~mm} \text {, o limite de escoamento máximo é incrementado em } \\
40 \mathrm{MPa} \text {, e para espessuras maiores que } 0,5 \mathrm{~mm} \text { e menores ou iguais a } 0.7 \mathrm{~mm} \text {, o valor máximo do limite de escoamento } \\
\text { é incrementado em } 20 \mathrm{MPa} \text {. }\end{array}$} \\
\hline \multicolumn{8}{|c|}{$\begin{array}{l}\text { D) Para bobinas e chapas de espessuras menores ou iguais a } 0,5 \mathrm{~mm} \text {, o valor mínimo de alongamento de ruptura diminui } \\
\text { em quatro unidades, e para espessuras maiores que } 0,5 \mathrm{~mm} \text { e menores ou iguais a } 0,7 \mathrm{~mm} \text {, o valor minimo do } \\
\text { alongamento de ruptura diminui em duas unidades. }\end{array}$} \\
\hline \multirow{2}{*}{\multicolumn{8}{|c|}{$\begin{array}{l}\text { e) Os valores de re } n \text { são válidos apenas para espessuras de produto maiores ou iguais a 0,5 mm e menores que } 2,00 \mathrm{~mm} \text {. } \\
\text { d) Para espessuras maiores que } 2,0 \mathrm{~mm} \text {, quando especificado no pedido de compra, o valor de } r \text { deve ser diminuido } \\
\text { em 0,2 mm. }\end{array}$}} \\
\hline & & & & & & & \\
\hline & & $0, \mathrm{cor}$ & & & & & \\
\hline
\end{tabular}

Bobinas de aço laminadas a frio e galvanizadas a quente com acabamento brilhante são empregadas para a confecção de calhas e telhas. Um lote deste material apresentou a formação de marcas durante o processo de fabricação dos produtos citados (telhas e calhas). Amostras contendo estas marcas, formadas durante a 
produção de telhas (com chapas de $0,35 \mathrm{~mm}$ ) e de calhas (com chapas de $0,48 \mathrm{~mm}$ ) foram fornecidas por uma trading no setor de aços para análise.

\title{
5.4 Requisitos de propriedades mecánicas
}

5.4.1 Os requisitos de propriedades mecânicas do aço săo dados na Tabela 2.

5.4.2 Quando especificada a garantia de valores de embutimento, a média aritmética dos valores de embutimento obtidos de trés ensaios nåo pode ser inferior ao valor especificado na Tabela 3. sendo que nenhum valor dos trés ensaios pode ser menor $0.3 \mathrm{~mm}$ que 0 da Tabela 3.

\begin{abstract}
5.4.3 Os valores de dureza sảo dados a título indicativo, podendo ser garantidos quando especificado no pedido de compra. Quando for estabelecida a obrigatoriedade de atendimento do ensaio de dureza, somente serảo garantidos os valores de um dos outros dois ensaios, traçăo ou embutimento, a opçăo do comprador. A média aritmética dos trés ensaios de dureza deve ser menor ou igual ao valor indicado na Tabela 2. Quando nảo for possivel ensaiar o material usando-se a dureza Rockwell escala B, pode ser utilizada outra escala. convertendo-se para a escala B os valores assim oblidos, segundo a ASTM E 140.
\end{abstract}

5.4.4 O produtor deve garantir as propriedades mecánicas indicadas na Tabela 2, a partir da data do recebimento do material pelo comprador, pelos seguintes prazos:

a) 30 dias. para os graus EM e EP.

b) seis meses para os graus EEP.

Figura 1. Prazo de validade das propriedades mecânicas conforme a norma ABNT NBR 5915:2008.

\subsection{Envelhecimento}

5.5.1 As bobinas e chapas finas laminadas a frio, principalmente as dos graus EM e EP, estão sujeitas ao fenômeno de envelhecimento, que se manifesta através do aumento da dureza e do limite de escoamento e da diminuição do alongamento e do embutimento, prejudicando a dutilidade do material.

5.5.2 O envelhecimento predispõe ao aparecimento de linhas de distensão quando as bobinas e chapas sofrem operação de estampagem. Estas linhas podem ser evitadas, passando-se adequadamente o material por uma desempenadeira de rolos imediatamente antes da estampagem. $O$ envelhecimento é fortemente influenciado pela temperatura, sendo tanto mais rápido quanto mais alta for a temperatura.

5.5.3 Por um prazo de seis meses, a partir da data em que o material for colocado à disposição do comprador, as bobinas e chapas finas dos graus EEP $1,2,3$ e 4 não podem apresentar alterações significativas em suas propriedades mecânicas nem defeitos causados por envelhecimento, tais como linhas de distensão, durante seu uso em operaçōes de conformação ou em ensaios de recebimento.

Figura 2. Descrição do possível envelhecimento do aço conforme a norma ABNT NBR 5915:2008..

A norma NBR 5915 (Fig. 2) indica as principais características e consequências do envelhecimento que são: perda de ductilidade (diminuição do alongamento), aumento do limite de escoamento do material e, principalmente, aparecimento de linhas de distensão (também conhecidas como bandas de Lüders). Provavelmente o aço não foi comercializado conforme a norma NBR 5915, porém o mesmo apresenta as mesmas características desta norma de qualidade. Os itens a seguir descrevem melhor os efeitos que o envelhecimento pode causar no material.

\subsection{Linhas de Distensão}

O patamar de escoamento é uma região de transição descontínua entre o regime elástico e o regime plástico. Nesta região, a tensão (ou o carregamento mecânico) permanece praticamente constante, surgindo bandas ou faixas de deformação na superfície do material, conhecidas como linhas de distensão ou bandas de Lüders, conforme ilustrado pela Figura 3. Este fenômeno é característico de aços baixo carbono laminados a quente (BQ's) ou laminados a frio e recozidos (sem laminação de encruamento).

As faixas mostradas na Figura 3 se propagam, à medida que a deformação plástica aumenta, podendo se apresentar tanto em corpos de prova de ensaios mecânicos ou durante o processamento de metais e/ou ligas que apresentam este fenômeno, conforme exemplificado na Figura 4. As linhas de distensão são restritas à superfície do material e o seu efeito só termina quando todo o material tiver se deformado. 

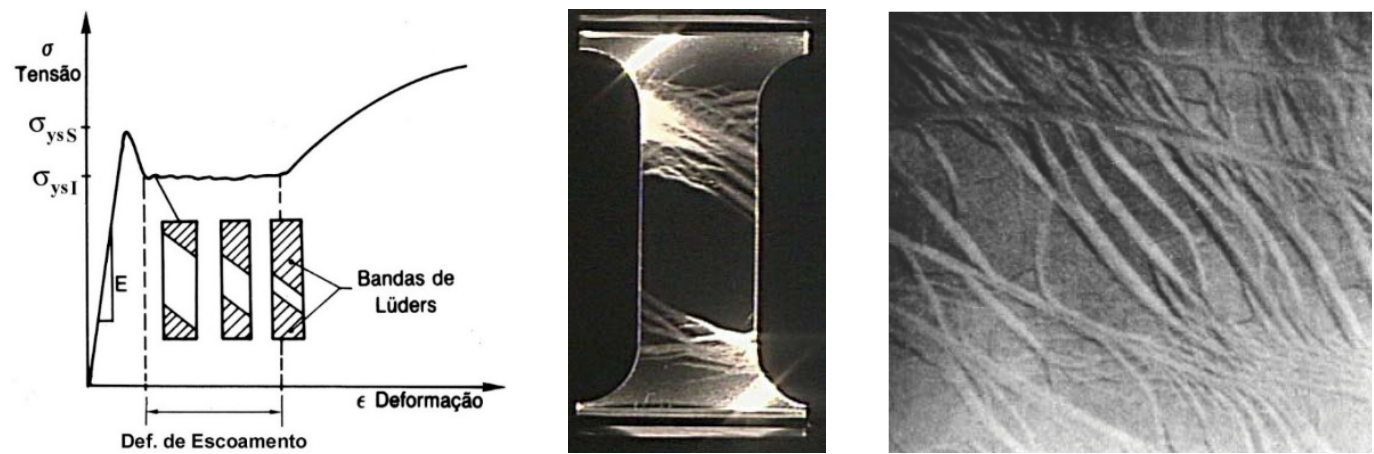

Figura 3. Descrição do possível envelhecimento do aço conforme a norma ABNT NBR 5915:2008..
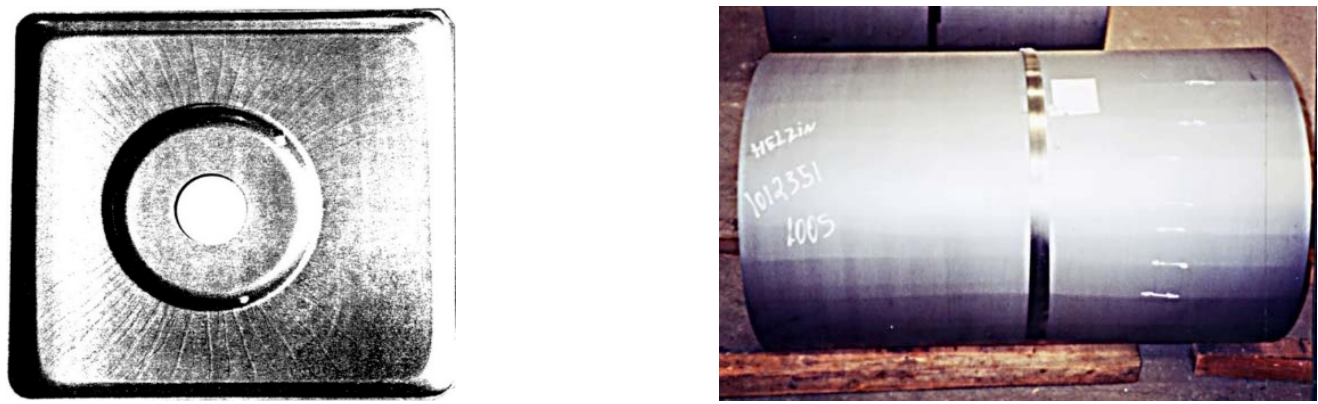

Figura 4. À esquerda: tentativa frustrada de se estampar uma peça com o surgimento de inúmeras "rugas" favorecidas pelo patamar de escoamento descontínuo. À direita: bobina de aço apresentando inúmeras marcas de "quebra de superfície", associadas diretamente às linhas de distensão ou bandas de Lüders.

Apesar de não ocasionar maiores problemas o patamar de escoamento e o surgimento das bandas de Lüders prejudicam o acabamento superficial de materiais que sofram pequenas deformações plásticas durante a conformação, especialmente nas peças estampadas que se destinam a superfícies expostas. Em todo o caso, para se evitar este fenômeno, recomenda-se:

- $\quad$ alterar a composição química da liga, como é o caso da adição de $\mathrm{Ti}, \mathrm{B}, \mathrm{Nb}$ no aço para a formação de carbonetos, eliminando os intersticiais livres presentes;

- $\quad$ pré-deformar a liga numa deformação superior à região de escoamento bem definido (skin pass rolling ou laminação de encruamento) de modo que a operação de conformação mecânica principal ocorra a partir da região de encruamento;

\subsection{Envelhecimento}

O patamar de escoamento é causado pela interação entre átomos de carbono livres (típicos de aços com baixo carbono) e a estrutura do aço. Este patamar pode ser retirado, por exemplo, com o uso de uma laminação de encruamento, conforme ilustrado na Figura 5.

Porém os átomos de carbono se difundem (se movimentam) dentro da estrutura do aço fazendo com que o patamar de escoamento e consequentemente as linhas de distensão voltem a aparecerem, conforme ilustrado na Figura 6. A rapidez e intensidade com que este fenômeno volta a aparecer depende da temperatura e do tempo a que foram submetidos o material, daí a origem dos limites de tempo para a validade do aço descritas na norma NBR 5915 reproduzidos na Figura 1. 


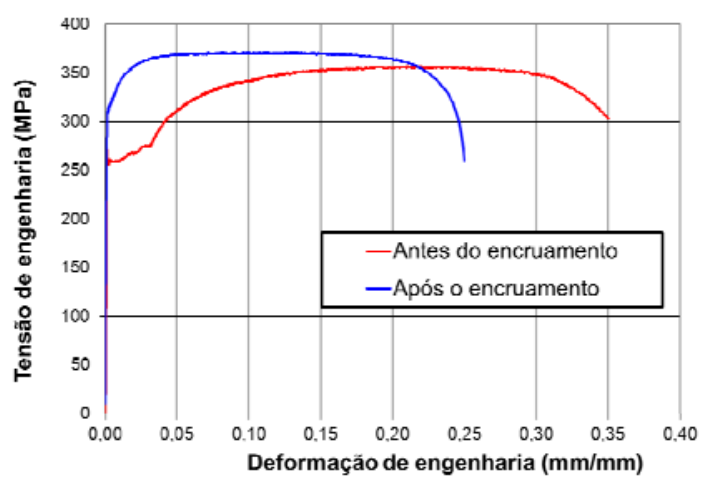

Figura 5. Exemplificação de uma curva tensão $x$ deformação de um ensaio mecânico de tração realizado em uma chapa de aço laminada a frio antes e depois de uma laminação de encruamento ou de acabamento (skin pass rolling).
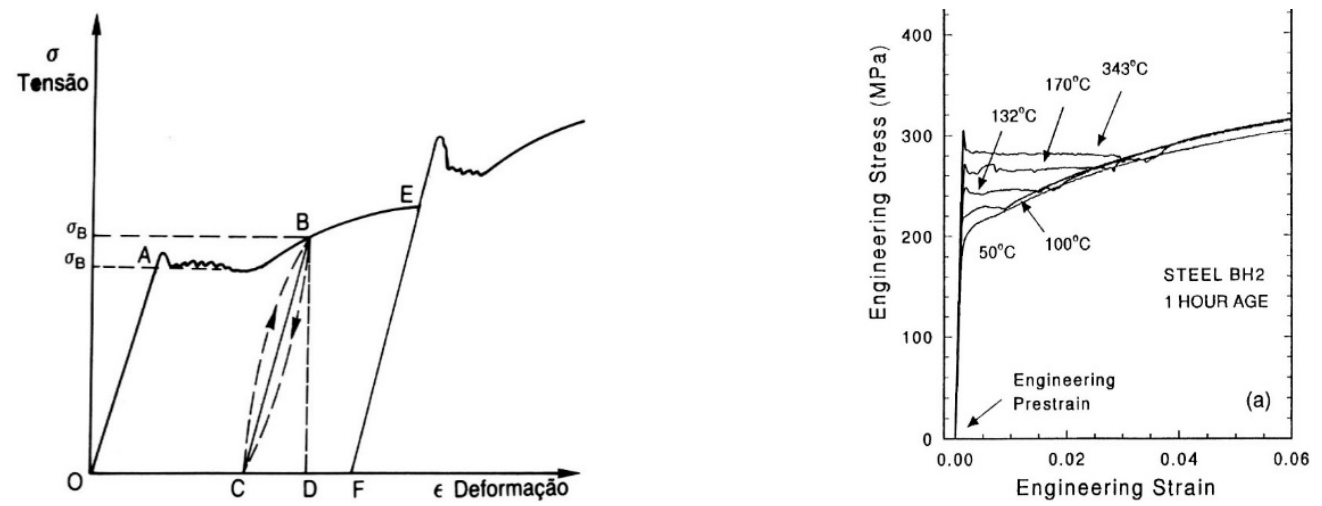

Figura 6. À esquerda: presença de escoamento descontínuo e patamar de escoamento (A) que é perdido após deformação plástica suficientemente intensa $(B)$ e recuperado após período de tempo suficientemente grande (E). À direita: variação do grau de endurecimento com a temperatura de envelhecimento em um aço baixo carbono com adição de fósforo (MEYERS e CHAWLA 1999.).

\subsection{Laminação de Encruamento (Skin Pass Rolling) em Material Galvanizado}

A laminação de encruamento é feita em aços após o processo de recozimento com o objetivo principal de retirar o patamar de escoamento que o aço, especialmente de baixo teor em carbono $(\% \mathrm{C}<0,15)$ passa a apresentar. A presença do patamar de escoamento torna o aço susceptível a formar linhas de distensão sob deformação plástica durante o processo de fabricação de produtos empregando este aço como matéria-prima.

A laminação de encruamento é feita reduzindo-se a espessura do material de 1 a $3 \%$, em função do tipo de aço, espessura e prática da siderúrgica. Esta operação é sempre feita após a última etapa de processamento do material que envolva alguma temperatura, como no processo de galvanização a quente. Isso é necessário, pois, conforme foi ilustrado na Figura 6, temperaturas mais elevadas aceleram o processo de envelhecimento do material.

No caso de materiais galvanizados a quente (hot dip galvanized) é importante tomar cuidado para que o mesmo não apresente linhas de distensão nas etapas anteriores à laminação de encruamento após a última etapa de processamento para não gerar características superficiais prejudiciais no material. $\mathrm{O}$ acabamento final da camada galvanizada será dado por esta etapa final de laminação de encruamento, portanto cuidados devem ser tomados para não gerar riscos, rugosidade irregular ou fora de 
padrão, após a laminação de encruamento (skin pass rolling). A Figura 7.a ilustra uma linha de galvanização padrão com a presença de um laminador de encruamento após a operação de galvanização final.
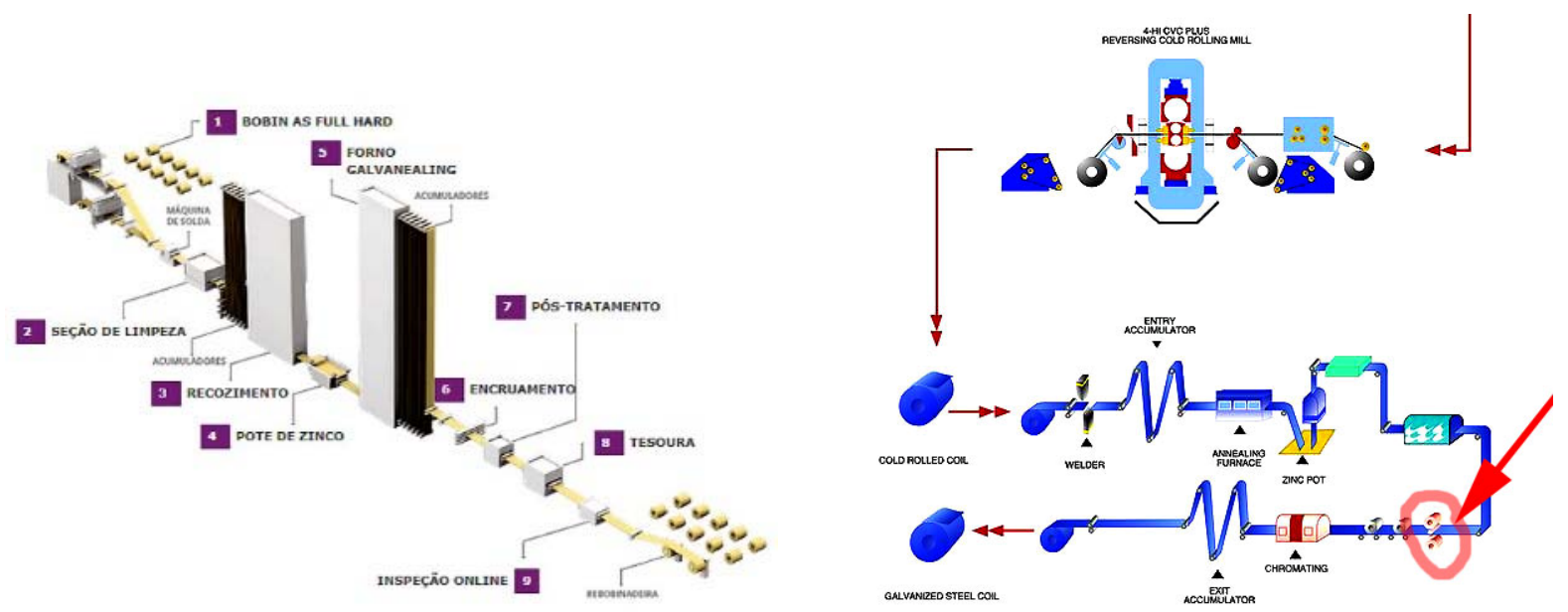

Figura 7. À esquerda: Linha de produção de bobinas laminadas a frio galvanizadas da USIMINAS (disponível em: http://usiminas.com/nossos-produtos/galvanizados-por-imersao-quente/). À direita: Linha de produção de chapas galvanizadas a quente (hot dip galvanized) com acabamento brilhante (disponível em: http://www.shanghaimetal.com/Corrugated_Galvanized_Steel_Sheet_Roofing_Sheet-pds534.html).

Além da galvanização é possível fazer um recobrimento leve sobre a superfície do material com cromo, o que oferece uma maior durabilidade e brilho da superfície. Quando este processo é empregado, geralmente por terceiros que processam o material direto da siderúrgica, uma laminação de acabamento ligeira é feira logo antes do recobrimento com cromo, processo feito a frio eletroliticamente. A Figura 7.b ilustra o fluxo de produção típico para a produção de materiais galvanizados com acabamento brilhante.

\section{MATERIAIS E MÉTODOS}

As fotos mostradas na Figura 8 referem-se às amostras do material recebido para análise nas espessuras medidas de $0,35 \mathrm{~mm}$ (telhas) e 0,47 e $0,48 \mathrm{~mm}$ (calhas). As marcas apresentadas estão ilustradas nestas figuras. O produto final não pode apresentar tais marcas, pois descaracterizaria o bom acabamento visado para estes produtos com o uso de material galvanizado brilhante. Por isso, o objetivo do presente trabalho é oferecer uma explicação para o aparecimento das marcas observadas nos componentes e indicar formas de evitar a sua formação, inclusive com a possibilidade de processamento da matéria-prima.

Com base nas informações apresentadas na introdução e considerando que o aspecto das chapas (Fig. 8) é muito similar ao aspecto (Fig. 4) de um material com patamar de escoamento/envelhecido (Fig. 5 e 6), as análises feitas foram orientadas a determinar se o material apresenta ou não este comportamento e se o mesmo sofreu uma laminação de encruamento final.

As três peças recebidas foram identificadas neste relatório conforme ilustrado na Figura 9. A identificação foi feita considerando a utilização final do material (calha ou telha). As duas amostras de calhas apresentam uma espessura de $0,47 \mathrm{~mm}$ ("Calha 01") e 0,48mm ("Calha 02") e a amostra de telha ("Telha 01") apresentava uma espessura de $0,35 \mathrm{~mm}$ conforme determinadas por micrômetro digital. 


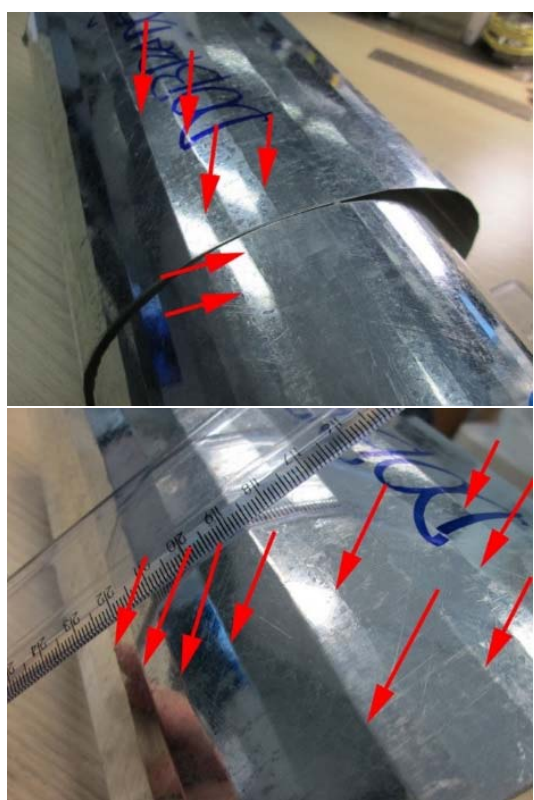

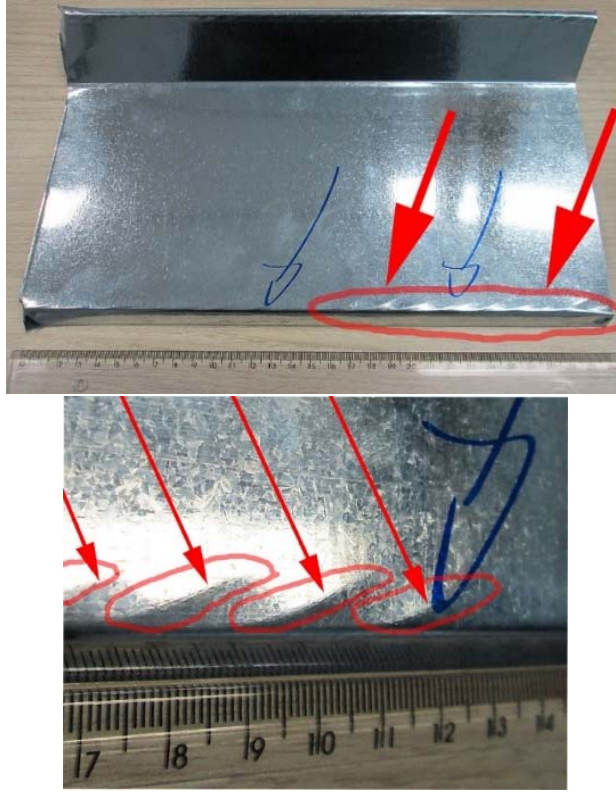

Telhas (espessura 0,35mm)
Calhas (espessuras 0,47 e $0,48 \mathrm{~mm}$ )

Figura 8. Fotos ilustrando as heterogeneidades apresentadas pelas chapas de aço analisadas. As fotos referem-se às amostras recebidas e as heterogeneidades estão destacadas nas imagens.

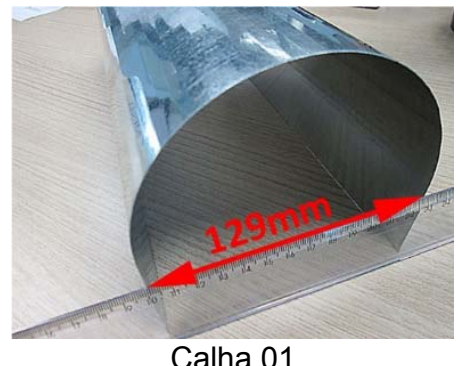

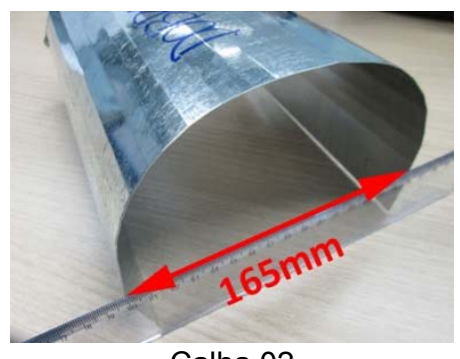

Calha 02

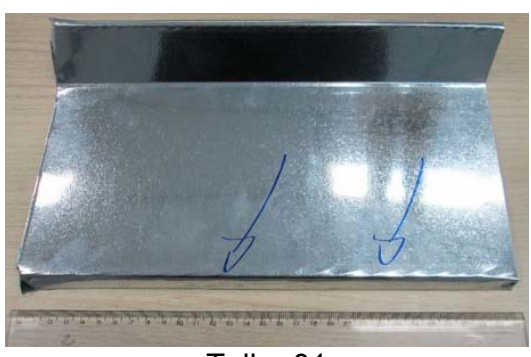

Telha 01

Figura 9. Identificação do material recebido para análise: "Calha 01" (com diâmetro menor); "Calha 02" (com diâmetro maior) e "Telha 01".

As peças foram inicialmente avaliadas superficialmente a nível macroscópico e depois analisadas através de um microscópio estereoscópico com capacidade de ampliação de até 40X. Corpos de prova (CPs) para ensaios de tração instrumentalizados (com extensômetria digital) foram retiradas das amostras nos sentidos longitudinal e transversal. Estes CPs foram ensaiados em uma máquina de tração com uso de extensômetro digital) de forma a serem obtidas as curvas tensão versus deformação ( $\mathrm{S} \times \mathrm{e})$ representativas do comportamento mecânico do material.

\section{RESULTADOS E DISCUSSÃO}

\subsection{Análise da Superfície}

Tanto as amostras das calhas quanto a amostra da telha apresentam uma superfície com grande presença de marcas na forma de linhas em regiões de deformação plástica. No caso das calhas, que foram submetidas a um processo de deformação foi mais suave e homogêneo, as marcas formadas apresentam uma distribuição relativamente homogênea de distância entre si, conforme ilustrado pelas fotos da Figura 10 e pelo gráfico da Figura 11. 


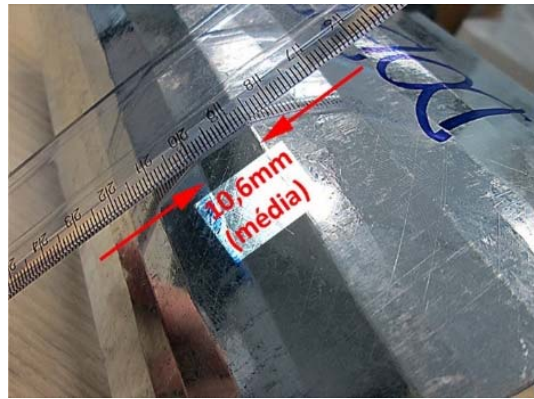

Figura 10. À esquerda: amostra "Calha 01". À direita: amostra "Calha 02". As fotos ilustram a formação de marcas alinhadas em direção ao raio de dobramento, características de linhas de distensão do aço das peças. A distância entre as marcas é relativamente constante.

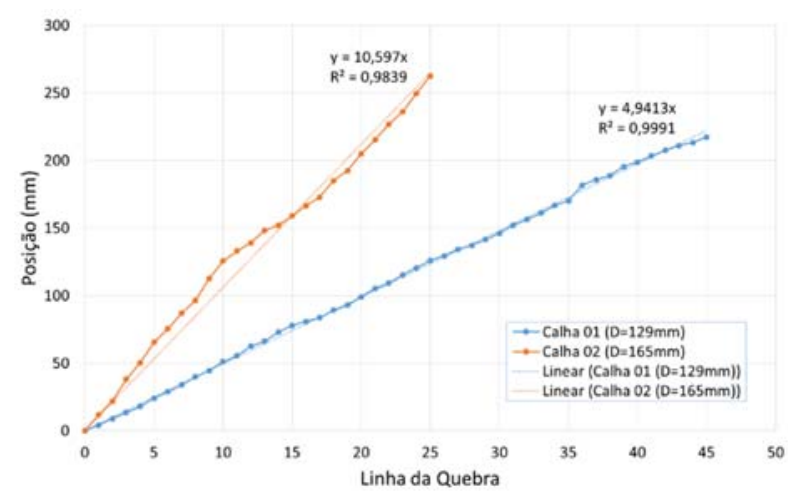

Figura 11. Distância entre as linhas de distensão das amostras de calhas recebidas.

No caso da amostra da telha, o forte dobramento necessário para conformar a chapa produziu várias linhas concentradas no raio da dobra, que se propagaram parcialmente para o interior da peça seguindo uma trajetória curva. As fotos da Figura 12 ilustram o aspecto destas linhas na amostra "Telha 01" nas duas regiões de maior deformação plástica efetuada no processo de fabricação.

As fotos da Figura 13 ilustram as linhas das descontinuidades registradas em maiores ampliações. Nestas figuras, fica claro que tais linhas são linhas de distensão, como foram exemplificadas na Fig. 4. O mesmo tipo de registro feito na Fig. 13 para a amostra "Calha 2" foi feito para a amostra "Telha 01". A partir desta comparação geométrica, as marcas serão designadas a partir neste relatório como sendo linhas de distensão, também conhecidas como bandas de Lüders ou mesmo quebras de superfície.
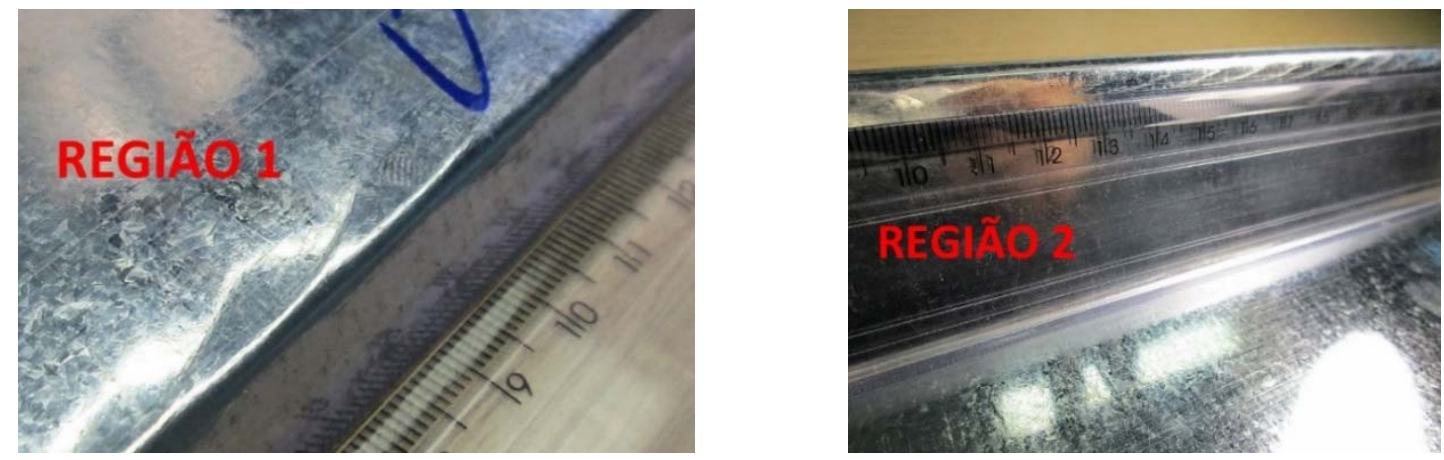

Figura 12. Aspecto das linhas de distensão observadas na amostra "Telha 01". As linhas ocorreram em 2 regiões da peça, nas quais durante a fabricação houver uma operação de dobramento mecânico. 

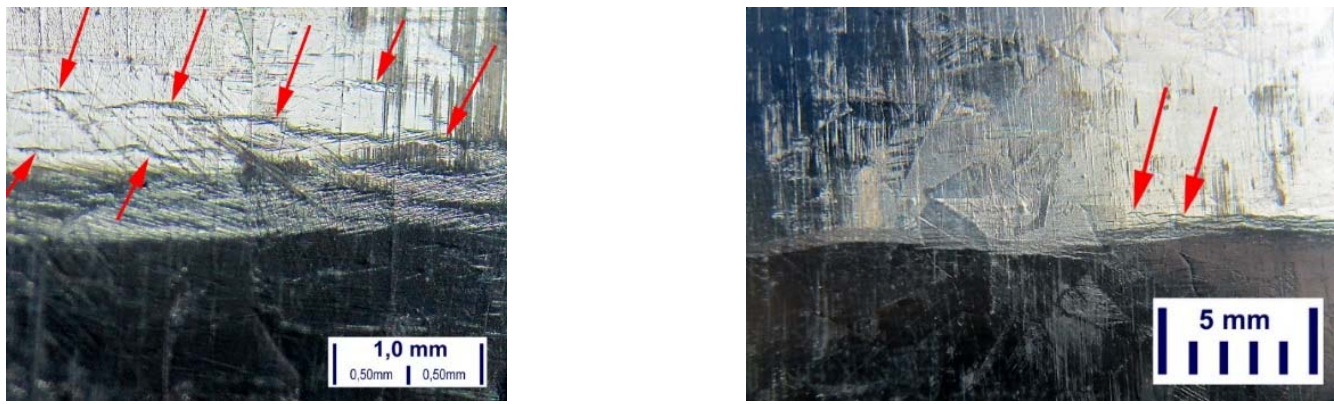

Figura 13. Aspecto das marcas lineares na superfície da amostra "Calha 02" com 40X e 10X de ampliação (da esquerda para a direita).

Outra característica avaliada na observação superficial foi a presença ou não de deformação plástica dos cristais da camada galvanizada a quente. Esta deformação plástica seria um indicativo de uma laminação de encruamento (skin pass rolling) nas amostras recebidas para análise. As fotos da Figura 14 ilustram que as superfícies das amostras apresentaram uma nítida diferença de altura entre os cristais da camada galvanizada que só poderiam ocorrer se o material não tivesse sofrido laminação de encruamento posteriormente à galvanização a quente. Com isso é presumível considerar que o material foi submetido a uma forte condição de envelhecimento devido a passagem do mesmo pelo banho de zinco (zinc pot - Fig. 7).
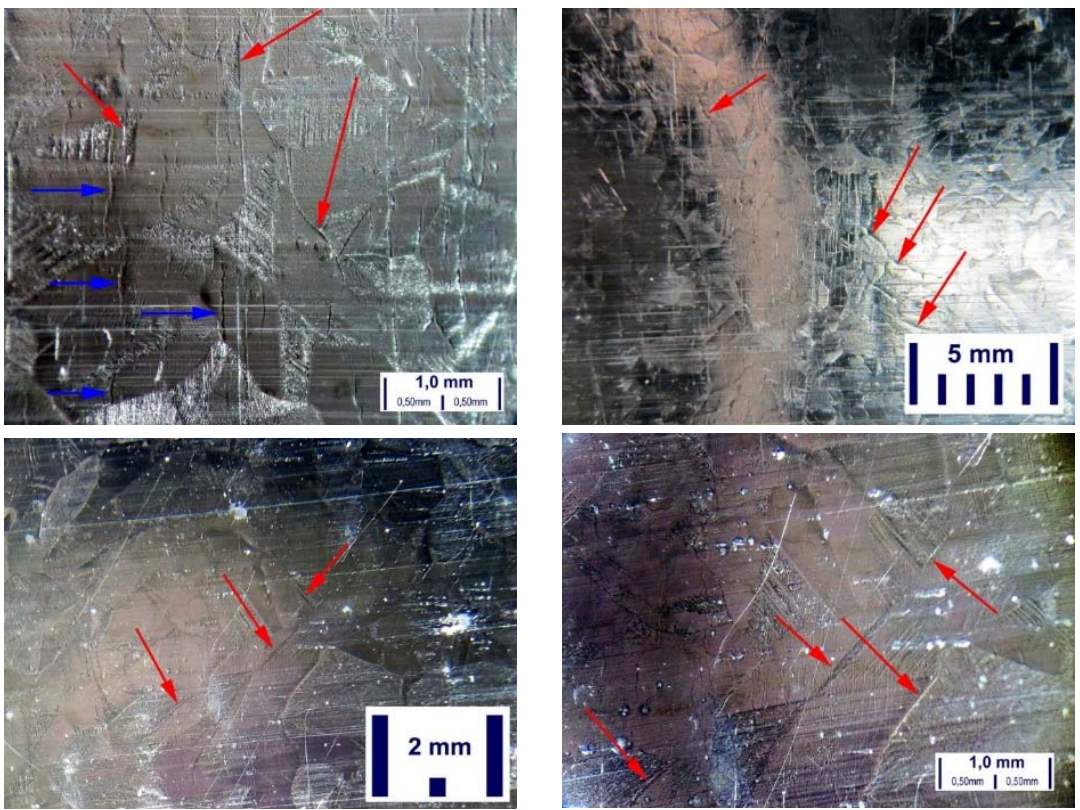

Figura 14. Fotos ilustrando a presença de degraus entre os cristais da camada galvanizada (algumas das quais indicadas pelas setas vermelhas inclinadas) que indicam que o material não sofreu laminação de encruamento após a galvanização. Na foto superior à esquerda as setas azuis horizontais indicam alguma das linhas de distensão presentes na amostra

Além disso, conforme sugerido pela Fig. 7, o material pode ter passado por uma etapa de encruamento anterior ao tratamento de galvanização a quente. Considerando que nesta condição, se o material envelhecer, este irá apresentar um comportamento mecânico muito desfavorável ao seu uso final. Conforme descrito pela NBR 5915 (Fig. 2) e pelo item 1.2 deste trabalho, um material nesta condição irá apresentar: baixa capacidade de encruamento, relação elástica (relação entre o limite de escoamento e resistência) próxima à unidade e baixo alongamento. 


\subsection{Ensaios de Tração}

Foram retirados Corpos de Prova (CPs) da amostra "Telha 01" no sentido transversal à laminação da chapa, conforme ilustrado na Figura 15.a. Três CPs (demarcados à esquerda na Fig.15) são do tamanho padrão $\left(L_{0}=50 \mathrm{~mm}\right)$ da norma ASTM E8M e os demais (demarcados à direita da Fig. 15) são tamanho subzise $\left(L_{0}=25 \mathrm{~mm}\right)$. Da amostra "Calha 02" foram retirados quatro CPs na direção longitudinal. Os ensaios foram realizados conforme a norma ASTM E8M (Standard Test Methods for Tension Testing of Metallic Materials [Metric]) com uso de extensômetro eletrônico, com precisão de $0,001 \mathrm{~mm}$, posicionado conforme mostrado na Figura 15.b e nas seguintes condições:

- $\quad$ menor velocidade de ensaio permissível pela norma $(5 \mathrm{~mm} / \mathrm{min}$.);

- $\quad$ temperatura ambiente controlada de $22^{\circ} \mathrm{C}$;

- máquina de tração eletromecânica controlada por computador (ENIC DL 10.000);

- $\quad$ com uso de célula de carga com sensibilidade de $3 \mathrm{~N}$ (ou 0,13\% nos ensaios em questão).

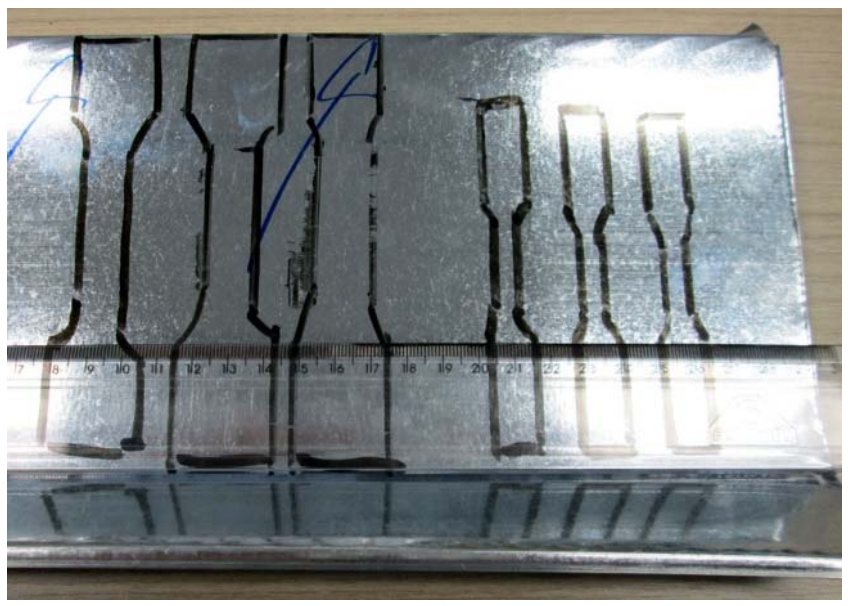

(a)

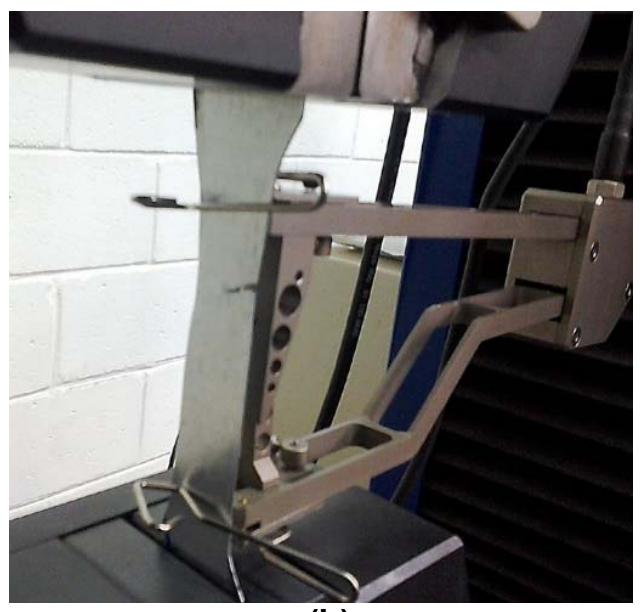

(b)

Figura 15. Foto ilustrando a demarcação para retirada de CPs de tração na amostra "Telha 01".

Durante os ensaios de tração foi possível observar claramente a formação de linhas de distensão (similares às mostradas na Fig. 4) e que estão exemplificadas nas fotos da Figura 16. A grande quantidade de linhas de distensão, sua intensidade e facilidade pelas quais as mesmas foram observadas e registradas ao longo do ensaio indicam a presença de um grande patamar de escoamento nestes materiais.

As curvas tensão versus deformação de engenharia obtidas para os CPs transversais (oriundos da amostra "Telha 01") e longitudinais (oriundos da amostra "Calha 02") estão apresentadas na Figura 17. Nestas curvas é nítido a condição de envelhecimento na qual se o aço das amostras, especialmente para o caso da amostra "Calha 02", nas quais o patamar de escoamento praticamente encontra-se mesclado com a pequena fase de encruamento do material.

Para facilitar a quantificação do patamar de escoamento em ambos os casos (amostras transversais e longitudinais), foi necessário, como mostrado na Figura 18, mudar a escala de visualização dos gráficos para permitir uma leitura mais precisa. No caso das amostras transversais (Fig. 17.a) o patamar variou entre 3 e $5 \%$. Já nas amostras longitudinais (Fig. 17.b) o patamar variou de 11 a $14 \%$. 

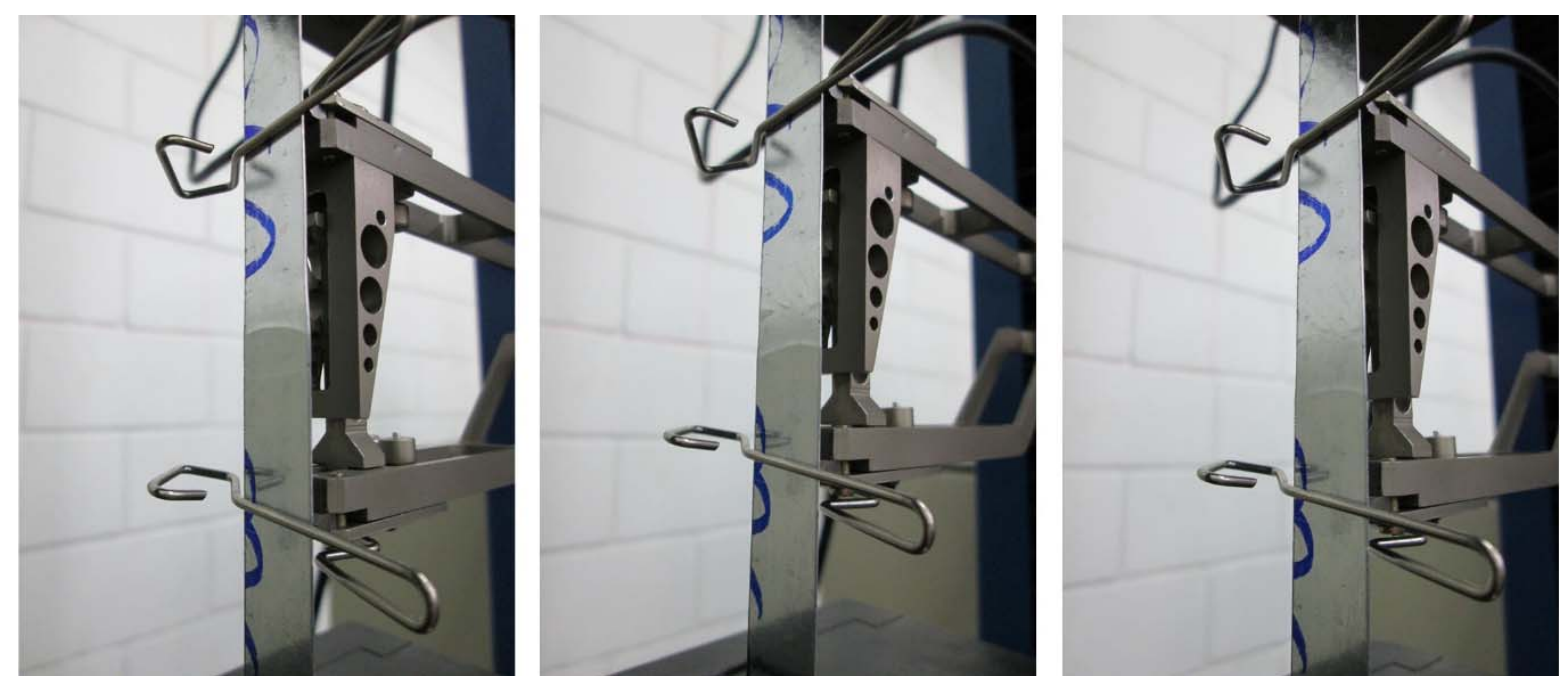

Figura 16. Fotos ilustrando a evolução das bandas de Lüders ou linhas de distensão (da esquerda para a direita) em um CP de tração longitudinal oriundo da amostra "Calha 02 " ao longo do ensaio de tração. A velocidade de tração do ensaio era de $5 \mathrm{~mm} / \mathrm{min}$. e o intervalo entre cada foto de 10 segundos o que dá uma diferença de deformação de $1,7 \%$ entre cada foto.

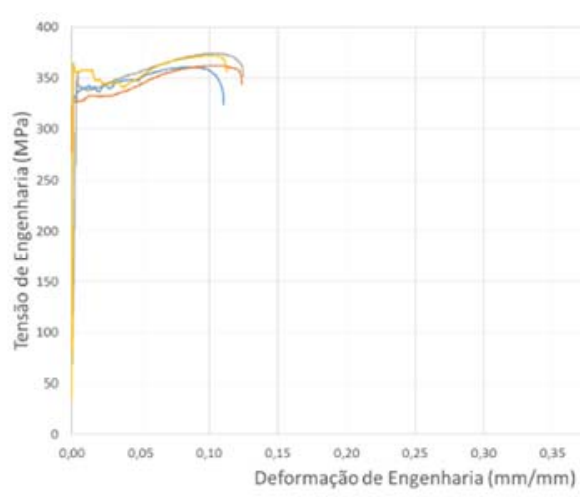

(a)

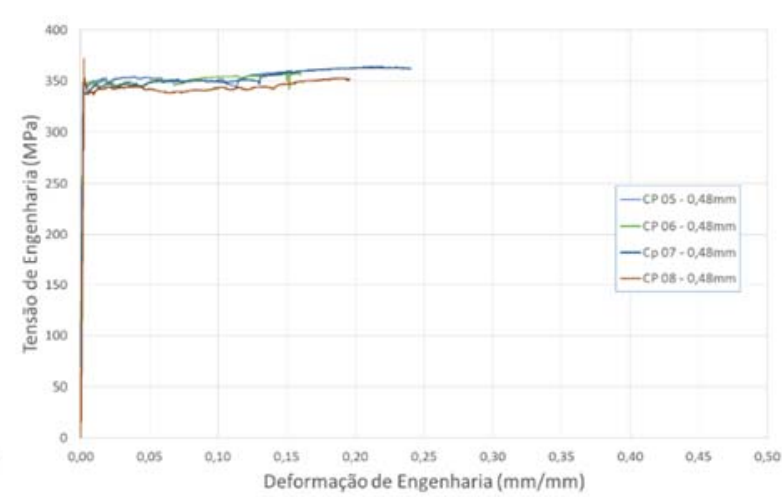

(b)

Figura 17. (a) Curvas tensão (S) versus deformação (e) de engenharia para CPs de tração transversais retirados da amostra "Telha 01". (b) Curvas tensão (S) versus deformação (e) de engenharia para CPs de tração longitudinais retirados da amostra "Calha 02".

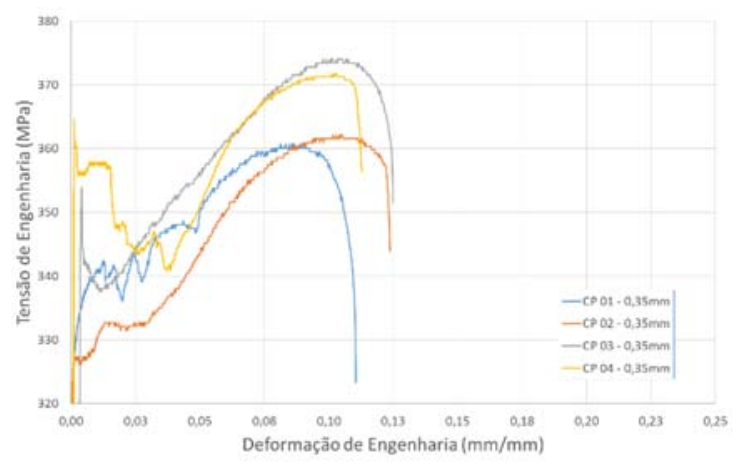

(a)

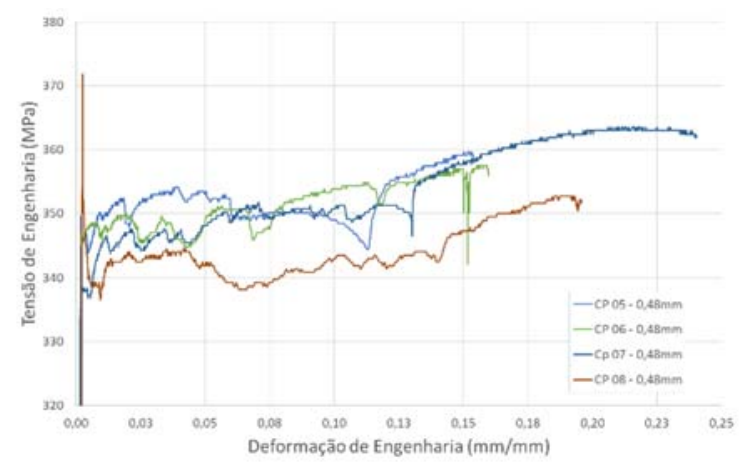

(b)

Figura 18. Curvas tensão versus deformação (Sxe) ampliadas. (a) CPs retirados na direção transversal da amostra "Telha 01". (b) CPs retirados na direção longitudinal da amostra "Calha 02".

A forma das curvas tensão versus deformação indicam um material que foi envelhecido por tempo (e provavelmente pela temperatura do processo de galvanização) após uma etapa de encruamento anterior. Esta condição é muito similar ao mostrado na Figura 6 deste artigo. 


\section{CONCLUSÃO}

Com base nas informações e nos dados gerados neste trabalho é possível concluir que:

- As descontinuidades observadas nas peças recebidas são linhas de distensão (também conhecidas como bandas de Lüders), pelo aspecto geométrico (vide Figs. 12 a 14) e pela distribuição relativamente coerente das mesmas em peças com raios de curvatura variados (vide Fig. 9 e gráfico da Fig. 11);

- O material recebido não foi processado através de uma laminação de encruamento após o tratamento de galvanização (imersão a quente em banho de zinco), devido ao aspecto superficial que ainda apresenta variação nos degraus dos cristais de zinco formados na sua superfície (vide Fig. 14);

o O material deve ter sido submetido a uma laminação de encruamento após a laminação a frio e antes da galvanização pelo fato da relação elástica observada nos ensaios de tração ter sido muito próxima à unidade, indicando que o limite de escoamento deste material está muito elevado em relação ao seu limite de resistência (vide Fig. 6);

- O aço das amostras encontra-se em adiantado grau de envelhecimento (strain aging) que foi precedido de uma operação de laminação de encruamento antes da etapa de galvanização de forma a deixar o presente material com uma condição de resistência mecânica e ductilidade não adequadas à aplicação do material.

Apesar da tendência de diminuir ainda mais a ductilidade deste material, recomendase que o mesmo seja processado por um laminador de encruamento, com um pequeno passe de redução da ordem de 1,5\% para o material na mesma situação da amostra "Telha 01 " (com $0,35 \mathrm{~mm}$ de espessura) conforme comportamento mostrado pelos gráficos de tensão versus deformação mostrados na Figura 17.a. No caso do material das amostras "Calha 01" e "Calha 02", considerando aplicáveis o comportamento mecânico apresentado pelas curvas tensão versus deformação da Figura 17.b, recomenda-se um passe de laminação de encruamento maior, da ordem de $3 \%$.

Após este passe de encruamento, o material deverá perder a maior parte do comportamento heterogêneo, porém o mesmo deve ser processado em um prazo curto (preferencialmente de 2 meses) e em operações de conformação não muito exigentes, já que a capacidade de deformação plástica do material processado deverá ser ainda mais restrita do que está atualmente.

\section{BIBLIOGRAFIA}

1 MORAIS, Willy Ank de; MAGNABOSCO, Antônio Sérgio; MENEZES NETTO, Eliana Bezerra de (Coord.). Metalurgia física e mecânica aplicada. 2a Edição. São Paulo: ABM, 2009. v. 1 e 2. 942 p.

2 GINZBURG, V. Metallurgical design of flat rolled steels. Nova York: Marcel Dekker, 2005. 744p.

3 LESLIE, W. C. The Physical Metallurgy of Steels. Techbooks, India, 1991.

4 MEYERS, M.A.; CHAWLA, K.K.; Mechanical Behavior of Materials. International Edition, Prentice-Hall International Inc., USA, 1999. 